JURNAL KACAPURI

JURNAL KEILMUAN TEKNIK SIPIL

Volume 4 Nomor 2 Edisi Desember 2021

\title{
PENGARUH PENAMBAHAN PASIR TERHADAP NILAI DAYA DUKUNG TANAH LEMPUNG TUMBANG RUNGAN
}

\author{
Junior Apik Pasaribu ${ }^{1}$, Fatma Sarie ${ }^{2}$, Okrobianus Hendri ${ }^{3}$ \\ ${ }^{123}$ Program Studi Teknik Sipil, Fakultas Teknik, Universitas Palangka Raya \\ E-mail: juniorpasaribu96@gmail.com¹, fatmasarie@jts.upr.ac.id ${ }^{2}$, dan \\ okrobianus@jts.upr.ac.id ${ }^{3} /$ HP.+6282277357723
}

\begin{abstract}
ABSTRAK
Konstruksi jalan di Tumbang Rungan mengalami penurunan yang diakibatkan kondisi tanah yang menurun. Penelitian ini bertujuan untuk mengetahui sifat fisik dan karakteristik tanah lempung Tumbang Rungan, mengetahui nilai CBR tanah sebelum dan sesudah dicampurkan dengan pasir. Penelitian ini dilakukan di laboratorium, untuk memperoleh kepadatan kering maksimum dan kabar air opyimum. Benda uji tanah lempung dicampur pasir dengan persentase 5\%,10\% dan 15\%, selanjutnya dilakukan pengujian. Untuk hasil penelitian didapatkan kadar air optimum mengalami kenaikan dari kadar air tanah asli 34,00\% menjadi 34,30\% untuk campuran pasir 5\%, 35,5\% untuk campuran pasir 10\%, 35,20\% untuk campuran pasir $15 \%$ dan kepadatan kering maksimum tanah mengalami peningkatan dari kepadatan kering maksimum tanah asli $1,212 \mathrm{gr} / \mathrm{cm}^{3}$ menjadi $1,226 \mathrm{gr} / \mathrm{cm}^{3}$ untuk campuran pasir $5 \%, 1,238 \mathrm{gr} / \mathrm{cm}^{3}$ untuk campuran pasir $10 \%, 1,248 \mathrm{gr} / \mathrm{cm}^{3}$ untuk campuran pasir $15 \%$. Untuk hasil CBR yang didapatkan mengalami kenaikan dari berat isi kering 95\% tanah asli 1,152 gr/cc menjadi 1,164 gr/cc untuk campuran pasir 5\%, 1,176 gr/cc untuk campuran pasir $10 \%$ dan 1,186 gr/cc untuk campuran pasir $15 \%$. Setelah data CBR didapatkan dilakukan perhitungan daya dukung. Diperoleh hasil perhitungan daya dukung tanah sebagai berikut untuk tanah asli $3,31 \mathrm{~kg} / \mathrm{cm}^{2}$, untuk campuran pasir $5 \% 4,70 \mathrm{~kg} / \mathrm{cm}^{2}$, untuk campuran pasir $10 \% 4,85 \%$ dan untuk campuran $15 \% 4,92 \mathrm{~kg} / \mathrm{cm}^{2}$. Kenaikan tertinggi didaya dukung tanah asli dan campuran $15 \%$.
\end{abstract}

Kata Kunci: Tanah Lempung, Kadar Air Optimum, Kepadatan Kering Maksimum, CBR, Daya Dukung.

\begin{abstract}
Road construction in Tumbang Rungan has decreased due to deteriorating soil conditions. The study aims to determine the physical properties and characteristics of the clay Tumbang Rungan soil, to determine the CBR value of the soil before and after mixing it with sand. The research was conducted in a laboratory, to obtain the maximum dry density and optimum water news. The test specimen is clay mixed with sand with a percentage of 5\%, 10\% and 15\%, then the test is carried out. For the research results, it was found that the optimum water content increased from the original groundwater content of $34.00 \%$ to $34.30 \%$ for $5 \%$ sand mixture, $35.5 \%$ for $10 \%$ sand mixture, $35.20 \%$ for $15 \%$ sand mixture and density. The maximum dry soil density increased from the maximum dry density of original soil $1,212 \mathrm{gr} / \mathrm{cm}^{3}$ to 1.226 $\mathrm{gr} / \mathrm{cm}^{3}$ for $5 \%$ sand mixture, $1.238 \mathrm{gr} / \mathrm{cm}^{3}$ for $10 \%$ sand mixture, $1.248 \mathrm{gr} / \mathrm{cm}^{3}$ for $15 \%$ sand mixture. The CBR results obtained have increased from the dry content
\end{abstract}


JURNAL KACAPURI

JURNAL KEILMUAN TEKNIK SIPIL

Volume 4 Nomor 2 Edisi Desember 2021

weight of $95 \%$ of the original soil from $1.152 \mathrm{gr} / \mathrm{cc}$ to $1.164 \mathrm{gr} / \mathrm{cc}$ for $5 \%$ sand mixture, $1.176 \mathrm{gr} / \mathrm{cc}$ for $10 \%$ sand mixture and $1.186 \mathrm{gr} / \mathrm{cc}$ for $15 \%$ sand mixture. After the CBR data is obtained, the carrying capacity is calculated. The results of the calculation of the carrying capacity of the soil are as follows for the original soil 3.31 $\mathrm{kg} / \mathrm{cm}^{2}$, for the $5 \%$ sand mixture $4.70 \mathrm{~kg} / \mathrm{cm}^{2}$, for the $10 \%$ sand mixture $4.85 \%$ and for the $15 \%$ mixture $4.92 \mathrm{~kg} / \mathrm{cm}^{2}$. The highest increase was in the original and mixed soil bearing capacity of $15 \%$.

Key word: Clay Soil, Optimum Moisture, Maximum Dry Density, CBR, Crrying Capacity.

\section{PENDAHULUAN}

Tanah didefinisikan secara umum adalah kumpulan dari bagian-bagian yang padat dan tidak terikat antara satu dengan yang lain (diantaranya mungkin material organik) rongga-rongga diantara material tersebut berisi udara dan air (Verhoef, 1994).

Tanah merupakan material yang terdiri dari agregat (butiran) padat yang tersementasi satu sama lain dan dari bahan bahan organic yang telah melapuk disertai dengan zat cair dan gas yang mengisi ruang-ruang kosong diantara partikel padat tersebut (Das, 1988).

Tanah merupakan material berpengaruh pada konstruksi bangunan serta konstruksi jalan. Ada berbagai macam cara dalam meningkatkan daya dukung tanah lempung yaitu dengan cara pemadatan dan cara bahan pencampur/tambahan tanah. Dalam permasalahan ini, peneliti mengkaji dengan cara penambahan bahan stabilisasi menggunakan pasir. Alasan menggunakan pasir karena mudah ditemukan dalam tiap lokasi. Penambahan pasir sebagai bahan campuran diharapkan dapat meningkatkan stabilitas tanah. Konstruksi jalan di Tumbang Rungan mengalami penurunan yang diakibatkan kondisi tanah yang menurun.

\section{Tujuan Penelitian}

Tujuan ini untuk mengetahui sifat fisik dan karakteristik tanah lempung Tumbang Rungan. Menganalisis pengaruh penambahan pasir terhadap tingkat kepadatan dan daya dukung tanah lempung Tumbang Rungan.

\section{METODE PENELITIAN}

\section{Lokasi Penelitian}

Tanah Lempung sebagai sampel penelitian berasal dari kelurahan Tumbang Rungan, Kecamatan Pahandut, Kota Palangka Raya, Provinsi Kalimantan Tengah, Indonesia. Untuk sampel pasir berasal dari tangkiling (Pal 38), Kota Palangka Raya, Provinsi Kalimantan Tengah, Indonesia.

\section{Pemeriksaan Sifat-sifat Tanah Asli}

Pemeriksaan sifat fisik asli meliputi:

\section{Pemeriksaan Kadar Air (Water Content)}


JURNAL KACAPURI

JURNAL KEILMUAN TEKNIK SIPIL

Volume 4 Nomor 2 Edisi Desember 2021

2. Pemeriksaan Berat Isi (Density Test)

3. Pemeriksaan Berat Jenis (Specific Gravity)

4. Pemeriksaan Batas-batas Konsistensi

a. Pemeriksaan Batas Cair (Liquid Limit)

b. Pemeriksaan Batas Plastis (Plastic Limit)

c. Pemeriksaan Batas Susut (Shrigkage Limit)

d. Indeks Plastisitas (Plasticity Indeks)

Pemeriksaan sifat mekanik tanah meliputi:

1. Pengujian Pemadatan Tanah (Compaction Test)

2. Pengujian California Bearing Rasio (CBR) Laboratorium (Laboratory CBR Test)

Tahapan Penelitian ini dapat dilihat pada bagian alir berikut ini:

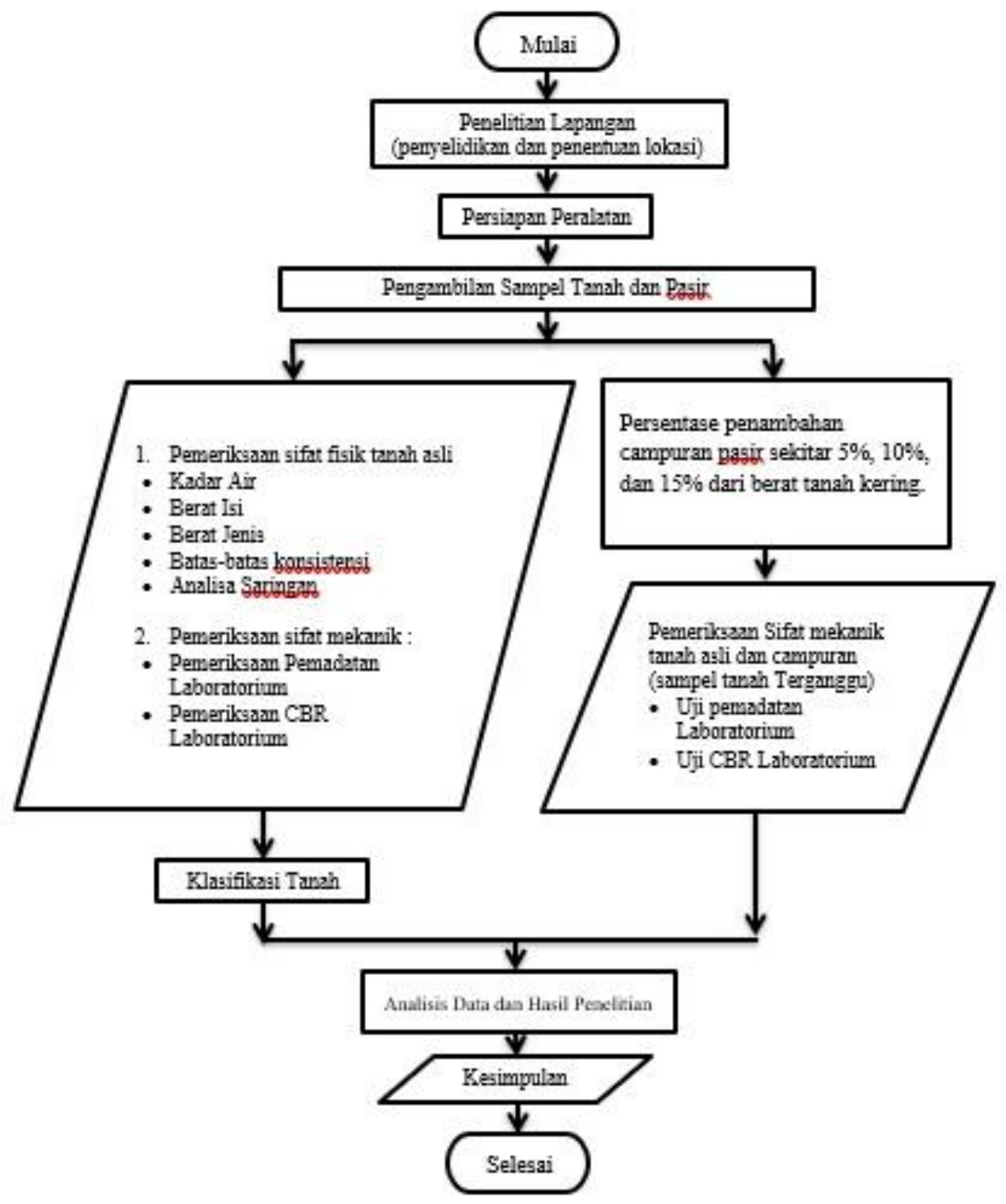

Gambar 1. Diagram alir kegiatan penelitian 


\section{Hasil Penelitian}

\section{HASIL \& PEMBAHASAN}

Untuk didapatkan sifat fisik dilakukan beberapa pengujian yang dilakukan di laboratorium meliputi kadar air, berat isi, berat jenis, dan batas-batas Atterberg. Pengujian sifat fisik menggunakan tanah tidak terganggu. Pengujian sifat fisik untuk mengklasifikasi tanah.

Tabel 1. Rekapitulasi Hasil Pengujian Sifat fisik

\begin{tabular}{|c|l|c|c|}
\hline No. & \multicolumn{1}{|c|}{ Jenis Pemeriksaan } & Satuan & Hasil \\
\hline 1. & Kadar Air (Water Content) & $\%$ & 31,66 \\
\hline 2 & Berat Isi (Water Content) & $\mathrm{Gr} / \mathrm{cm}^{3}$ & 2,72 \\
\hline 3 & Berat Jenis (Specific Gravity) & $\mathrm{Gr} / \mathrm{cm}^{3}$ & 2,72 \\
\hline 4 & Batas-batas Atterberg & & \\
\hline & a. Batas Cair (Liquid Limit) & $\%$ & 45,00 \\
\hline & b. Batas Plastis (Plastic Limit) & $\%$ & 25,63 \\
\hline & c. Indeks Plastisitas (Plastic & $\%$ & 19,37 \\
\hline & Indeks) & $\%$ & 14,05 \\
\hline 5 & Analisis Saringan & $\%$ & 100 \\
\hline & a. Lolos Saringan No. 10 & $\%$ & 79,51 \\
\hline & b. Lolos Saringan No. 40 & $\%$ & 51,92 \\
\hline & c. Lolos Saringan No. 200 & & \\
\hline
\end{tabular}

\section{Klasifikasi Tanah}

\section{Sistem Klasifikasi AASHTO}

Berdasarkan dari hasil presentase lolos analisis saringan nomor 200 sebesar 51,92\%, batas cair sebesar 45,00\%, Indeks Plastisitas (IP) sebesar 19,37\%, maka hasil klasifikasi tanah dari tabel AASHTO yang diuji adalah tanah berlempung dengan kondisi sedang sampai buruk dan termasuk dalam klasifikasi grup A-7-5. 
JURNAL KACAPURI

JURNAL KEILMUAN TEKNIK SIPIL

Volume 4 Nomor 2 Edisi Desember 2021

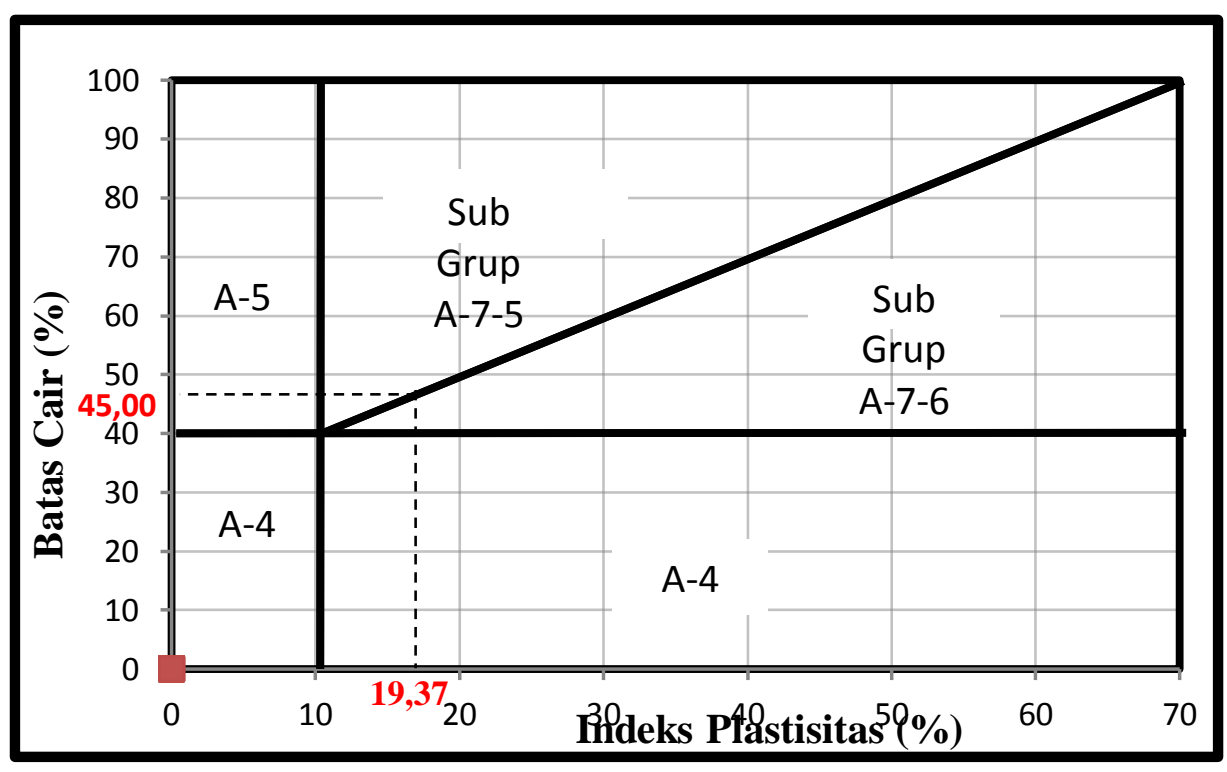

Gambar 2. Klasifikasi Tanah Berdasarkan Sistem Klasifikasi AASHTO

\section{Sistem Klasifikasi USCS}

Berdasarkan klasifikasi USCS dapat disimpulkan bahwa jenis tanah yang didapat adalah lempung inorganic dengan plastisitas rendah-sedang lempung lanau, pasiran, kerikilan dan lempung kurus.

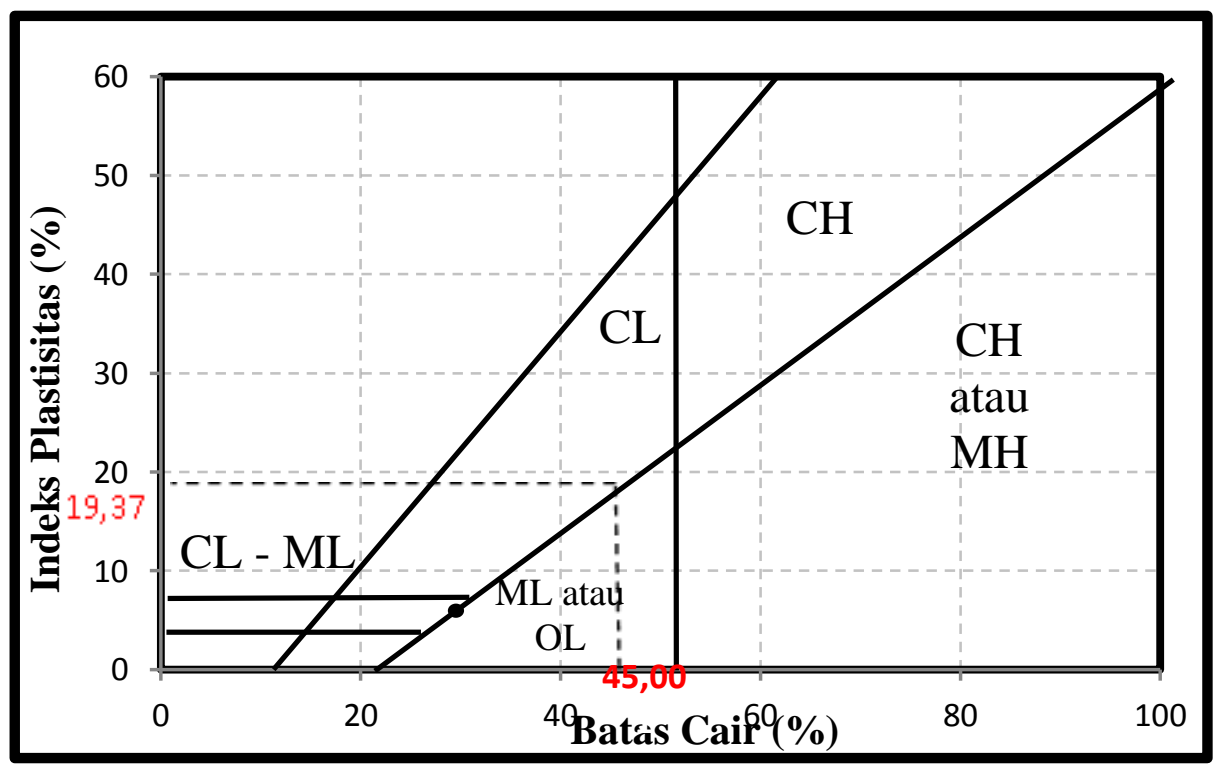

Gambar 3. Klasifikasi Tanah Berdasarkan Sistem Klasifikasi AASHTO 


\section{Pengujian Sifat-sifat Mekanik Tanah}

Pengujian sifat-sifat mekanik di laboratorium meliputi pemadatan laboratorium dan CBR laboratorium.

Tabel 2. Hasil Rekapitulasi Pengujian Pemadatan Laboratorium

\begin{tabular}{|c|c|c|}
\hline Variasi Campuran & $\begin{array}{c}\text { Kadar Air } \\
\text { Optimum (\%) }\end{array}$ & $\begin{array}{c}\text { Kepadatan } \\
\text { Maksimum (g/cc) }\end{array}$ \\
\hline Tanah Asli & 34,0 & 1,212 \\
\hline Tanah Asli + Pasir 5\% & 34,3 & 1,226 \\
\hline Tanah Asli + Pasir 10\% & 35,5 & 1,238 \\
\hline Tanah Asli + Pasir 15\% & 35,2 & 1,248 \\
\hline
\end{tabular}

Tabel 3. Hasil Rekapitulasi Pengujian CBR Laboratorium

\begin{tabular}{|c|c|c|}
\hline Variasi Campuran & $\begin{array}{c}\text { Kepadatan } \\
\text { Maksimum }\left(\mathrm{g} / \mathrm{cm}^{3}\right)\end{array}$ & $\begin{array}{c}\text { Nilai CBR RENCANA } \\
(\%)\end{array}$ \\
\hline Tanah Asli 0\% & 1,152 & 4,05 \\
\hline Tanah Asli + Pasir 5\% & 1,164 & 4,99 \\
\hline Tanah Asli + Pasir 10\% & 1,176 & 5,40 \\
\hline Tanah Asli + Pasir 15\% & 1,186 & 5,60 \\
\hline
\end{tabular}

\section{Hubungan Daya Dukung Tanah dengan CBR Rencana}

Daya dukung tanah dasar (DDT) merupakan salah satu parameter yang digunakan dalam nonogram penetapan indeks tebal perkerasan (ITP). Nilai daya dukung tanah dasar didapat dari hari grafik kolerasi CBR tanah dasar terhadap DDT, secara analitis nilai DDT dengan menggunakan persamaan berikut (Sukirman,1999).

$$
\mathrm{DDT}=4,3 \log \mathrm{CBR}+1,7
$$

Keterangan:
DDT : daya dukung tanah dasar

CBR : Nilai CBR tanah dasar

Tabel 4. Rekapitulasi Hasil Hubungan Daya Dukung Tanah Dasar dengan CBRRencana

\begin{tabular}{|c|c|c|}
\hline Variasi Campuran & $\begin{array}{c}\text { Nilai CBR RENCANA } \\
(\%)\end{array}$ & $\begin{array}{c}\text { Nilai Daya Dukung } \\
\text { Tanah Dasar }\left(\mathrm{kg} / \mathrm{cm}^{2}\right)\end{array}$ \\
\hline Tanah asli 0\% & 4,05 & 3,31 \\
\hline Tanah asli + Pasir 5\% & 4,99 & 4,70 \\
\hline Tanah asli + Pasir 10\% & 5,40 & 4,85 \\
\hline Tanah asli + Pasir 15\% & 5,60 & 4,92 \\
\hline
\end{tabular}


JURNAL KACAPURI

JURNAL KEILMUAN TEKNIK SIPIL

Volume 4 Nomor 2 Edisi Desember 2021

Nilai daya dukung terbesar terjadi di penambahan pasir $15 \%$ yaitu $4,92\left(\mathrm{~kg} / \mathrm{cm}^{2}\right)$. Nilai yang telah didapat selanjutnya akan dilihat pada grafik hubungan antar CBR dengan DDT (daya dukung tanah) pada Gambar 4.

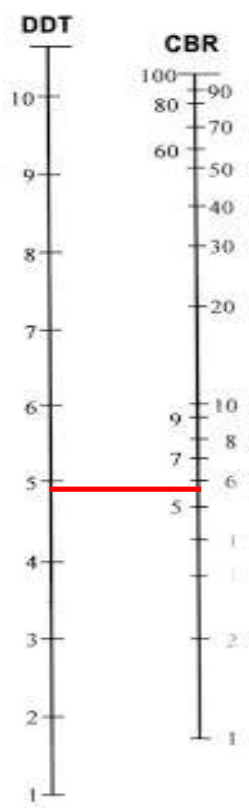

Gambar 4. Grafik Nilai CBR dengan DDT

\section{Kesimpulan}

\section{PENUTUP}

Berdasarkan hasil analisis data yang telah dilakukan maka diperoleh kesimpulan sebagai berikut:

1. Hasil pengujian sifat-sifat fisik tanah didapat nilai kadar air $(\mathrm{w})=31,66 \%$; berat isi kering $(\mathrm{\gamma})=1,75 \mathrm{~g} / \mathrm{cm}^{3}$; berat jenis $(\mathrm{Gs})=2,72 \mathrm{~g} / \mathrm{cm}^{3}$; batas-batas Atterberg yaitu $L L=45,00 \% ; P L=25,63 \% ; P I=19,37 \% ; S L=14,05 \%$; analisis saringan persentase lolos saringan no $200 \mathrm{~mm}=51,92 \%$. Menurut AASHTO tanah diklasifikasikan tanah berlempung, dalam kelompok A-7-5, dan menurut USCS dapat disimpulkan bahwa klasifikasi tanah yang didapat adalah lempung inorganic dengan plastisitas rendah-sedang lempung lanau, pasiran, kerikilan dan lempung kurus. Sifat mekanik tanah nilai pemadatan tanah asli 0\% OMC= $34,00 \%, \gamma_{\mathrm{d} \max }=1,212\left(\mathrm{~g} / \mathrm{cm}^{3}\right)$, Penambahan pasir tertinggi komposisi tanah asli $100 \%$ dan pasir $15 \%$ didapat $O M C=35,20 \%, \gamma_{\mathrm{d} \text { max }}=1,248\left(\mathrm{~g} / \mathrm{cm}^{3}\right)$, maka disimpulkan terjadi kenaikan $0,036 \%$ dari tanah asli ke persentase penambahan pasir yang tertinggi.

2. Hasil pengujian nilai CBR laboratorium:

a. Sampel tanah asli $0 \%$ didapat Nilai $\mathrm{CBR}=4,05 \%$. 
JURNAL KACAPURI

JURNAL KEILMUAN TEKNIK SIPIL

Volume 4 Nomor 2 Edisi Desember 2021

b. Nilai $\mathrm{CBR}$ tanah asli dan campuran pasir, 5\% $\mathrm{CBR}=4,99 \% ; 10 \% \mathrm{CBR}=$ $5,40 \% ; 15 \% \mathrm{CBR}=5,60 \%$. Persentase optimum terjadi pada $15 \%$ dengan komposisi tanah asli $100 \%$ + pasir 15\%, maka dapat disimpulkan terjadi kenaikan $1,55 \%$ dari tanah asli ke persentase penambahan pasir yang tertinggi.

3. Nilai daya dukung tanah mengalami kenaikan dari tanah asli:

a. Daya dukung tanah asli sebesar: $3,31\left(\mathrm{~kg} / \mathrm{cm}^{2}\right)$

b. Daya dukung tanah asli dan campuran pasir, $5 \%$ DDT $=4,70\left(\mathrm{~kg} / \mathrm{cm}^{2}\right), 10 \%$ DDT $=4,85\left(\mathrm{~kg} / \mathrm{cm}^{2}\right), 15 \%$ DDT $=4,92\left(\mathrm{~kg} / \mathrm{cm}^{2}\right)$. Kenaikan tertinggi di daya dukung tanah asli dan campuran $15 \%$.

\section{Saran}

Berdasarkan hasil dari penelitian dan analisis data yang dilakukan, maka disarankan sebagai berikut:

1. Untuk penelitian selanjutnya disarankan untuk menambahkan persentase pasir agar memperoleh data hasil yang optimal.

2. Untuk melihat kenaikan atau penurunan persentase CBR, sebaiknya dilakukan penambahan rencana pemeraman.

3. Perlu pengawasan intensif dilakukan pada pembuatan sampel di laboratorium dan peralatan yang digunakan pada saat penelitian.

4. Pengujian CBR ini memenuhi syarat sehingga mendekati kepadatan maksimal tidak lebih dari 6\%, dan untuk penelitian selanjutnya perlu di perhatikan persentase penambahan pasir sehingga mendapatkan hasil yang optimal.

\section{DAFTAR PUSTAKA}

Bowles, J. 1984. Sifat-Sifat Fisik dan Geoteknis Tanah (Mekanika Tanah), Edisi Kedua. Jakarta: Erlangga.

Canonica, L. 1991. Memahami Mekanika Tanah. Bandung: Angkasa.

Craig, R.F. 1987. Mekanika Tanah, Edisi Keempat, Terjemahan Budi Susilo Soepandji. Jakarta: Erlangga.

Das Braja M., 1988. Mekanika Tanah Prinsip-Prinsip Rekayasa Geoteknis, Jilid 1. Jakarta: Erlangga.

Grim, R.E. 1953. Clay mineralogy. New York: Mc Graw Hill Book Company Inc.

Hardiyatmo, H.C. 1999. Mekanika Tanah I. Jakarta: Gramedia Pustaka Umum.

Hardiyatmo, H.C. 2002. Mekanika Tanah I (3rd ed). Yogyakarta: Gadjah Mada University Press. 
Hardiyatmo, H.C. 2006. Mekanika Tanah I. Yogyakarta: Gajah Mada University Press.

Hardiyatmo, H.C. 2010, Analisis dan Perancangan Fondasi. Yogyakarta: Gajah mada University Pers.

Sukirman, S. 1999. Dasar-Dasar Perencanaan Geometrik Jalan. Bandung: Nova

Tjokrodimulyo, K. 1992. Bahan Bangunan. Yogyakarta: Universitas Gadjah Mada.

Verhoef, P.N.W. 1994. Geologi Untuk Teknik Sipil. Jakarta: Erlangga.

Wesley, L.D. 1977. Mekanika Tanah (Jilid VI). Jakarta: Badan Penerbit Pekerjaan Umum. 